\title{
PREGNANCY, COMPLICATED BY PREECLAMPSIA: FETOPLACENTAL COMPLEX IMMUNE DEADAPTATION AND HISTOSTRUCTURAL FEATURES
}

DOI: 10.36740/WLek202001119

\author{
Pavlo V. Yavorskyi' ${ }^{1}$, Vitalii M. Zozulia' ${ }^{1}$, Oleh Ya. Vanchuliak' ${ }^{2}$, Marta S. Garazdiuk² \\ 'COMMUNAL HIGHER EDUCATIONAL ESTABLISHMENT "ZHYTOMYR MEDICAL INSTITUTE" OF ZHYTOMYR REGIONAL COUNCIL, ZHYTOMYR, UKRAINE \\ 2HIGHER STATE EDUCATIONAL ESTABLISHMENT OF UKRAINE"BUKOVINIAN STATE MEDICAL UNIVERSITY", CHERNIVTSI, UKRAINE
}

\begin{abstract}
The aim: to study and compare the features of the interleukins levels and morphological changes of placenta at various stages of preeclampsia.

Materials and methods: 109 pregnant women with preeclampsia of varying severity (study group) and 30 pregnant women with uncomplicated pregnancy (control group) were examined. Immunohistochemical method, proinflammatory interleukins levels, morphological and morphometric analysis of peripheral and central placental areas biopsies on the optical and electron-microscopic level have been used.

Results: Morphofunctional changes in the placenta in case of preeclampsia and the increase in the expression level of the transforming growth factor have a series of regular stages from the formation, strain and disruption of adaptive mechanisms with more pronounced signs of morphological immaturity of parenchymal and stromal elements of the placenta, especially in the area of syncytiotrophoblast and spiral vessels. The degree of clinical manifestation of preeclampsia has a correlation relationship with IL-10 deficiency and with the increase in TNF-a, stimulation of macrophage-protein production that contributes to the change in the ratio of Thl / Th2, which are antagonists and inhibit each other's development.

Conclusions: The severity of the preeclampsia course correlates with the state of morphofunctional changes in the placenta and changes in the ratio of the pro- and antiinflammatory interleukins.
\end{abstract}

KEY WORDS: interleukins, ultramorphological placental changes, preeclampsia

Wiad Lek. 2020;73(1):99-103

\section{INTRODUCTION}

The problem of preeclampsia in pregnant women remains one of the most complex and relevant in obstetric practice [1-6] and requires further study.

Despite constant attention to the problem of gestosis in pregnant women around the world, until now the question of the etiology and mechanisms of the development of pathological processes remain controversial, and none of the existing theories can not convincingly substantiate the causes of this complication of pregnancy. In recent years, more importance in the development of gestosis is caused by a violation of the immune system of the pregnant woman [2].

The urgency of the role of the placenta in the pathological course of pregnancy is extremely high, especially in the development of various gestational complications $[3,4,6]$, such as preeclampsia.

The pre-eclampsia frequency remains high, and this is why the systematic and complex study of morphofunctional placental changes and the state of interleukins in the development of small asymptomatic and atypical preeclamptic forms in obstetric practice [4] as factors that can significantly affect the growth of this complication can not be overestimated.

\section{THE AIM}

To study and compare the features of the interleukins levels and morphological changes of placenta at various stages of preeclampsia.

\section{MATERIALS AND METHODS}

109 pregnant women with preeclampsia of varying severity (study group) and 30 pregnant women with uncomplicated pregnancy (control group) were examined. Used clinical, laboratory, ultrasound, doplerometric, immunohistochemical, biophysical methods of investigation. Morphological and morphometric analysis was carried out in 93 biopsies of peripheral and central placental areas on the optical and electron-microscopic level. Also the state of proinflammatory interleukins (IL)-2, TNF- $\alpha$ and anti-inflammatory - IL-10 in 32 pregnant women with varying degrees of severity were studied. The placenta was taken immediately after delivery and was fixed in Buen's fluid. Paraffin sections were stained with Hematoxylin by Mallory. The quantitative composition of interleukins was estimated by a solid-phase enzyme-linked immunosorbent method. The ELISA test system, DIACLON (France) was used for measurement. The research was carried out according to the manufacturer's methods. 


\section{RESULTS}

In the study, it was discovered that the usual triangulation of Tsangmejistra was observed in $13 \%$ of cases with mild preeclampsia, $28.6 \%$ - with moderate and $62.8 \%$ of cases with severe preeclampsia. Combining symptom at all stages of preeclampsia was to some extent hypertension, which varied from $56 \%$ of cases with a mild degree of severity up to $98 \%$ with severe gestosis. In women with preeclampsia, the increase in the level of proinflammatory interleukins has been noted.

Thus, it was found that proinflammatory IL - 2 in the first half of pregnancy in women who make up the risk group for the development of gestosis are from $19.01 \pm 1.03 \mathrm{pg} /$ $\mathrm{ml}$ (and their level continues to increase in the second half of pregnancy) to $76.36 \pm 3.77 \mathrm{pg} / \mathrm{ml}(\mathrm{p}<0.05)$, and there is a fairly high level of TNF-a throughout pregnancy in women with gestosis compared to the physiological course of pregnancy. In the physiological course of pregnancy, this indicator was lower and was $54.34 \pm 3.32 \mathrm{pg} / \mathrm{ml}$. In the development of preeclampsia, it tended to grow from $64.83 \pm 3.32 \mathrm{pg} / \mathrm{ml}$ at mild progression to $128.81 \pm 14.64$ $\mathrm{pg} / \mathrm{ml}$ in severe cases.

At the same time, there is a decrease in the activity of anti-inflammatory interleukins during pregnancy. Thus, IL-10 with $23.66 \pm 0.93 \mathrm{pg} / \mathrm{ml}$, which was observed during mild pregnancy, decreased to $18.15 \pm 0.92 \mathrm{pg} / \mathrm{ml}$ in severe preeclampsia during the second half of pregnancy $(\mathrm{p}<0$, $05)$, which indicates the corresponding reaction of the main immune mechanisms of the systemic inflammatory reaction.

When conducting postpartum placenta scopia, we note that the decidual septum between the lobes is thickened, the blood vessels of the surface of the mucous membrane varicose changed, there are about 30\% hypertrophied villi with destructive changes in the trophoblastic epithelium. Most of the vessels of microvilli are sliced with erythrocytes, they have signs of intracellular edema of endothelial cells and ultrastructural lesions.

Thus, the revealed morphological changes of the placenta indicate an unfavorable course and restriction of compensatory possibilities of the placenta in preeclampsia, and are not signs of intracellular regeneration.

The state of intervertebral gaps is characterized by significant expansion combined with a thickened basal membrane of the cytotrophoblast, expansion of the capillary mesh and vascular edema, expansion of the endoplasmic mesh tubules, and increased content of free ribosomes.

To capillaries with dystrophically altered endothelial cells, activated macrophages adjoined closely. Along with the defeat of the parenchymal and stromal elements of the blood capillaries, changes in the cells of syncytiotrofoblast were manifested. The changes found in the syncytiotrophoblast epithelium showed a development of dystrophic and necrotic changes. The feature of the defeat is the statement of the phenomena of apoptosis. In syncytiotrophoblast, dystrophic changes were observed in the cytoplasm, nucleus and cytoplasmic membrane. Due to pronounced edema in intensticium space, syncytiotrophoblast does not adhere tightly to the basement membrane. On the surface of the cytoplasmic membrane there was a decrease in the number of microvilli. The cytoplasm was characterized by the appearance of vacuoles, which merged with each other and formed the balloon structures (see Figure 1).

In the cytoplasm of the cells there was an uneven location of the organelles. Mitochondria formed so-called mitochondrial complexes, aimed at compensating for losses of energy resources of cells. There were enlarged mitochondria. Cell nuclei had an elongated or rounded shape. Nucleolome was a denser, zigzag form. Nuclear chromatin was located in the form of a depth with a tendency for perinuclear localization (see Fig. 2).

Along with this there were cells with pronounced apoptotic changes. In such cells, the contours of the nucleus become irregular due to the deep invagination of the nuclear membrane. The latter was thinned and hyperosmophilic. The aggregated nuclear chromatin, in the form of large lumps, was located along the inner surface of the nucleolums. Cytoplasm of the cells was hyperosmophilic, condensed.

Endothelial cells looked like thinned cells with a homogeneous cytoplasm. The cytoplasmic membrane is swollen, without clear contours, focal lobed. Often swelling or dehydration of the cytoplasmic matrix was observed with variations in its electron density. The shape and volume of the cell, as well as the desquamation of the fragmented cytoplasm in the lumen of the vessel, were altered. At the same time the number of lysosomes increased in the cytoplasm, indicating the possibility of developing cell autolysis (see Figure 3).

Activated macrophages adjoined closely to capillaries with dystrophically altered endothelial cells. Along with the defeat of the parenchyma-stromal elements of the blood capillaries, changes in the cells of syncytiotrofoblast were revealed.

Thus, the study showed that in women with preeclampsia of moderate severity, there is not only a violation of the rheological properties of the blood and damage to the parenchymal and stromal elements of the vessels of the microcirculatory bed, but also the defeat of the structural elements of syncytiotrophoblast. These changes indicate the tendency of local activation of regenerative processes in the direction of substitution of normal placental tissue as a result of an ischemic injury. In pregnant women with preeclampsia of mild degree, $39.2 \%$ to $72.6 \%$ of destructively altered villi are found, and at a severe degree their number is even more increasing. In the ultrastructural study, karyopicnosis, caryoreksis of cytoplasm, symplastotrophoblast and basement membrane of trophoblastic epithelium were detected. In the stroma of the villi (according to the stages of preeclampsia), the number of lymphocytes and macrophage-like cells increases progressively, and the number of elements of the fibroblastic series decreases. The described structural changes tended to increase depending on the degree of preeclampsia.

The structural reorganization of the chorionic villi with preeclampsia of mild degree is more often detected 


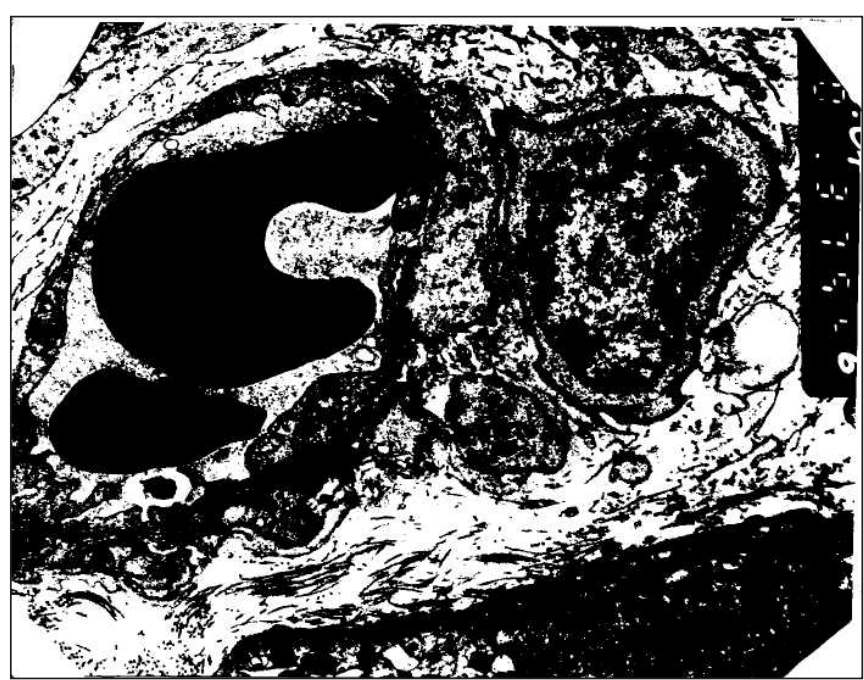

Fig. 1. Capillary with adhesion of erythrocyte to the surface of the endothelial cell. Activated macrophage, balloon structures in swollen interstitial villi in patients with preeclampsia of moderate severity. Electrogram X-12000.

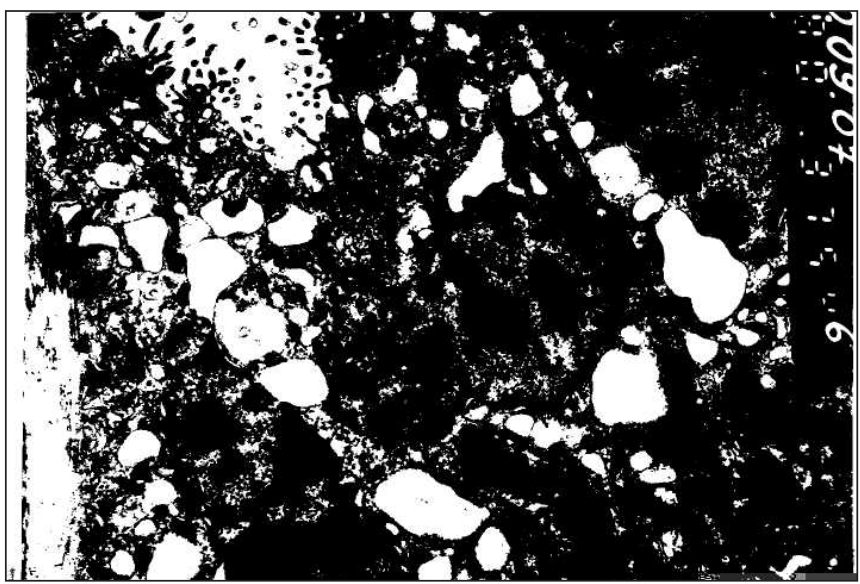

Fig. 2. Syncytiotrophoblast cells with vacuolated cytoplasm, nucleus with chromatin in the form of a lumps in a patient with preeclampsia of moderate severity. Electrogram X-15000.

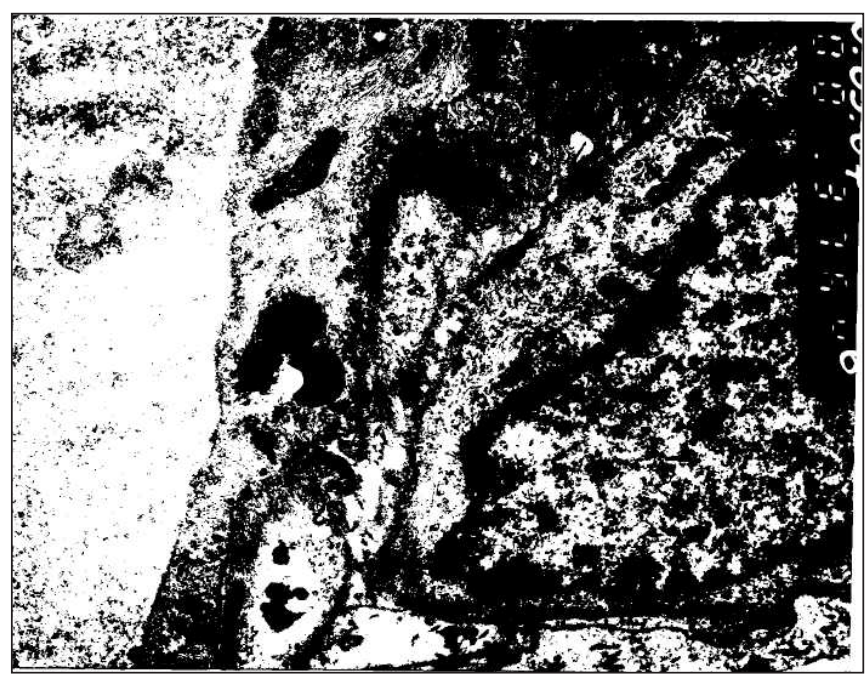

Fig. 3. Dystrophically altered endothelial cell with numerical lysosomes, edema and felted cytoplasmic membrane in a patient with preeclampsia of moderate severity. Electrogram X-20000. on the periphery, which allows the central part of the placenta to compensate for these disorders at this stage. In marked hemodynamic violations of hypercoagulation changes in placenta are of a total character with signs of decompensation of its function. Correlation with the use of biophysical methods of research with their comparisons with the histological structure of the placenta suggests that, regardless of the initial mechanism of triggering the pathological process, improvement of the utero-placental blood flow primarily depends on the rheological properties of the blood and the condition of the chorionic villi. The findings are clearly correlated with the state of interleukins, which stimulate a powerful humoral immune response.

Unlike preeclampsia of moderate severity, in preeclampsia of severe degree signs of apoptosis have been observed in a significant number of epithelial cells in the form of sshrinkage of cell membranes, cellular contraction, lysosomal and nuclear fragmentation. Appeared significant amount of cytoplasmic outgrowths and apoptotic cells.. Significant vacuation of the cytoplasm and organelles was observed. The same changes were detected in the syncytiotrophoblast structures. Against the backdrop of structural changes, there was a violation of the rheological properties of the blood with the subsequent development of the "sludge phenomenon", the stasis and the microthrombotic formation, and, in the vessels of the microcirculatory bed, there were small centers of re-endothelialization, and the newly formed cells in the regions of re-endothelialization were characterized by moderate osmophilia, the presence of cytoplasmic processes, increased number of mitochondria, and cluster of lysosomes. The nucleus contained an electron-dense nucleoplasm, a grainy chromatin, aggregated into the lumps. It is located eccentrically in the inner layer of the nuclear membrane. The edges of the nucleus were uneven, perinuclear space was expanded in places. The nucleus had an electron-dense appearance, a compact or loose structure.

The cell membrane of the endothelial cells had microvilli and faint invaginations. The endoplasmic reticulum was represented by short, small tubules. These plate complex contained both small vesicles and extended cisterns, located in different sections of the cytoplasm.

Thus, the study showed that in the fetoplacental complex of women with preeclampsia of severe degree there is a deep defeat of structural elements like blood vessels of hemo-microcirculation with a violation of the rheological properties of blood, and syncytiotrofoblast. Common to them was the same alternative process in the form of apoptosis. However, the beginning of the apoptotic process in the conducted studies had some differences, depending on the structure of the fetoplacental complex. In syncytiotrophoblast, in areas along with nuclei that had signs of apoptosis, there was a disappearance of microvilli, a cytoplasmic seal and the appearance of osmophilic membrane structures. Endothelial cells, the nuclei of which had signs of initial apoptosis, lost intercellular contacts and separated from unaffected cells. Subsequently, the apoptotic process acquired the same characteristics for all cell populations. 


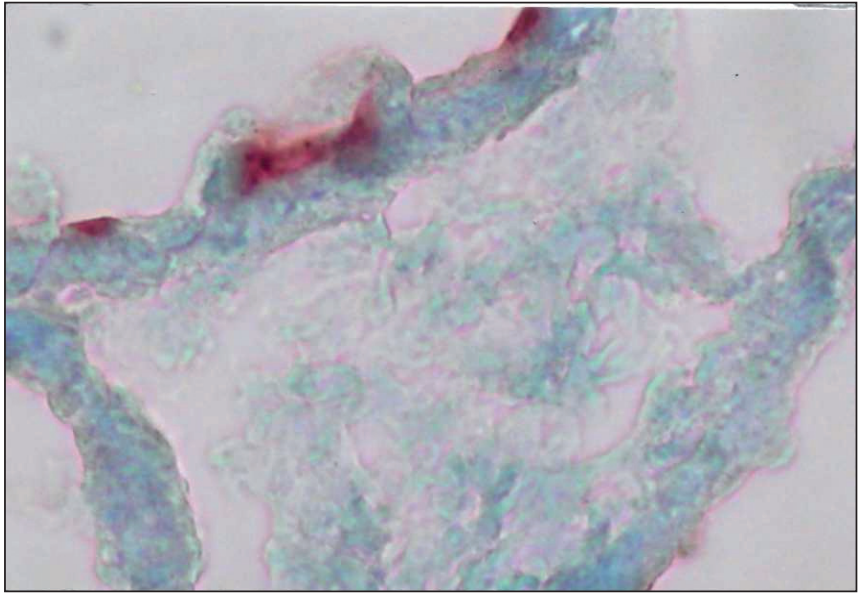

Fig. 4. A fragment of chorionic villus with focal expression of TNF-a antigen in syncytiotrophoblast epithelium (1 - 2 points) in a patient with light preeclampsia. Indirect streptavidin-peroxidase method for detecting TNF-a antigen expression. $X-400$.

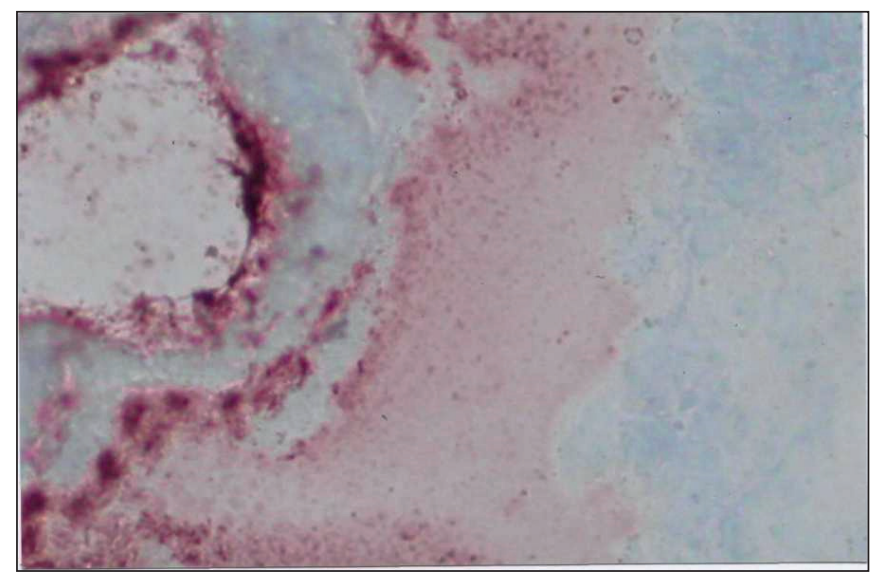

Fig. 5. Endometrial fragment with pronounced expression ofTNF-a antigen (3 score) of a patient with preeclampsia of severe severity. Indirect streptavidinperoxidase method for detecting TNF-a antigen expression. X-200.

So, summarizing our studies of ultrastructural changes of endothelial cells in the microcirculatory channel of the fetoplacental complex during pregnancy with physiological course, it was found that endothelial cells completely retain their structure and function accordingly.

\section{DISCUSSION}

In preeclampsia in pregnant women, the morphological changes in the placenta are characterized by significant changes in the structural and functional activity of endothelial cells, a violation of the cell structure with the development of the initial stage of apoptosis. Studies have shown that in the syncytiotrophoblast epithelium, activation of lipid peroxidation occurs, as evidenced by the presence of the syncytiotrophoblastic membrane in the cytoplasm of the osmophilic structures. The latter accumulate in the cytoplasm from the formation of balloon structures .

Intercellular contacts are changing, there are signs of immune inflammation, a decrease in the number of fibrinoids, which confirms the growth of vascular permeability and the development of inflammatory response. Along with this there are ischemic and degenerative-dystrophic changes in the cells of syncytiotrofoblast. Violation of the rheological properties of the blood and damage to the parenchymal and stromal elements of the blood vessels of the microcirculation leads to fibrinoidal necrosis of the vascular wall of the villi, as a result of lymphocytic-macrophage infiltration there is a vasospasm, edema and thrombosis. Structural elements of syncytiotrophoblast are deeply affected and chorionic villus fibrosis develops.

In the background of morphologic changes in placenta, the level of IL-10 in pregnant women with preeclampsia of a mild degree does not differ significantly from that of pregnant women with a physiological course in the first half of pregnancy ( $p>0.05)$. In severe preeclampsia, IL-10 levels decreased twofold $(11.25 \pm 0.54 \mathrm{pg} / \mathrm{ml}(\mathrm{r}=0.48, \mathrm{p}<0.05))$.

The emphasis on the displacement of interleukin pools in the direction of cell-mediated inflammatory reaction suggests that in preeclampsia, the disorder of the microcirculation is an unfavorable background for the course of pregnancy. This is the result of a disturbance of the placenta function due to the inflammatory immune response by activating the maternal systemic inflammatory responses, which is manifested by the increased release of proinflammatory IL-2 and TNF - $\alpha$ interleukins.

The growth of IL-2 in severe preeclampsia is 1.89 times higher than that for a mild degree of gestosis $(p<0.05)$. A direct correlation between the level of IL-2 and the preeclampsia development rate $(\mathrm{r}=0.71, \mathrm{p}<0.05)$ was revealed.

The level of TNF - $\alpha$ tends to grow only in the early stages of the development of preeclampsia, that is, with a mild and moderate manifestation of the course $(\mathrm{p}<0,05)$, and with severe preeclampsia, a sharp decrease in its level occurs, which obviously indicates the breakdown of certain parts of cellular immunity. The TNF- $\alpha$ antigen expression intensity index was 3 points, the rate of prevalence of the process reached $75.6 \pm 6.7 \%$.

The revealed changes correlated with changes in the endometrium. In the endometrium, there was a focal-diffuse localization of the TNF- $\alpha$ antigen. The prevalence of the process ranged from 15 to $40 \%$, with an average prevalence rate of $27.5 \pm 4.2 \%$ (see Figure 4 ).

In addition, expression of the antigen of the factor of necrosis of the cells was detected in the endothelial cells of the microcirculatory bed and at the intensity of the coloration by the semi-quantitative method in balls was 1 point [7]. The process was of a focal nature and was within $10 \%$. The highest intensity was recorded in the epithelium of the glands, in the cells of the macrophage-lymphocyte series, in the decidual cells, as well as in the cover uterine epithelium.

In pre-eclampsia, an increase in proinflammatory cytokine (TNF- $\alpha$ ) is observed both in intensity and in the extent of prevalence (Fig. 5). Under the influence of TNF - $\alpha$, not only the activity of the inflammatory process, but also the processes of thrombophilia increases, as TNF - $\alpha$ has a prothrombogenic effect. The realization of this effect is manifested by the 
development of a sludge phenomenon and microthrombotic formation, which promotes the development of irreversible changes in the fetoplacental complex and causes fetal hypoxia. The growth of the expression level of the transforming growth factor indicates the immaturity of parenchymatous-stromal elements of the placenta and placental bed (see Figure 5).

At the same time, a sharp decline in the IL-10 with 23.66 $\pm 0.93 \mathrm{pg} / \mathrm{ml}$, which occurs in the mild course, to $17.91 \pm$ $0.43 \mathrm{pg} / \mathrm{ml}$, corresponding to severe preeclampsia, indicates suppressor the activity of this IL in patients with preeclampsia of the lung and medium $(\mathrm{p}<0,05)$. This fact also indicates the disruption of the functioning of the humoral suppressor of the immune system, which at the early stages of the development of precalampy provides protection of the fetus from the destructive effects of the mother's immune system under the influence of proinflammatory interleukins, prevents the suppression of compensatory immune mechanisms and, as a result, inhibits the development of preeclampsia. As a conclusion: the higher the IL-10 in the early stages of pregnancy, the course of it is more physiological, and vice versa, the lower is it, so the preeclampsia development increases.

In pre-eclampsia, IL-10 deficiency, coupled with TNF-a growth, stimulates the production of macrophage-proinflammatory protein, which binds to monocytes of blood and $\mathrm{T}$ lymphocytes, promotes changes in the ratio of Th $1 /$ Th 2 subpopulations inducing an immune response toward Th-1, i.e. in the direction of anti-suppressor, pro-inflammatory reversal of the local immune system. The growth of the expression level of the transforming growth factor confirms the immaturity of the parenchymatous and stromal elements of the placenta, especially in the area of syncytiotrophoblast and spiral vessels. The latter have an immature structure in which smooth muscle cells predominate.

Such vessels are capable of contraction and cause deterioration of blood supply to the placenta, which leads to endothelial dysfunction, placental ischemia and the development of ofinfarction. Violation of hemodynamics of placental blood flow causes placental hypertension and increased resistance of deciduals of arterial vessels.

\section{CONCLUSIONS}

Histo-ultrastructural analysis of placental changes and dysfunctional changes in the state of the cellular and humoral immunity links showed a correlation between the severity of pre-eclampsia and the nature of the structural and functional transformation of cell and tissue elements of the placenta during preeclampsia and the role of the imbalance of immune bonds of proinflammatory and anti-inflammatory interleukins as a factor blocker of proinflammatory interleukins inhibitor of a cell response and a stimulator of humoral response.

\section{REFERENCES}

1. Roberts JM, Escudero C. The placenta in preeclampsia. Pregnancy Hypertension: An International Journal of Women's Cardiovascular Health. 2012;2(2):72-83. https://doi.org/10.1016/j.preghy.2012.01.001
2. Sidorova IS, Nikitina NA. Preeklampsiya v tsentre vnimaniya vrachapraktika [Preeclampsia in the focus of a practitioner's attention]. Akusherstvo i ginekologiya. 2014; 6:4-9. (In Russian).

3. Uzan J, Carbonnel M, Piconne 0 et al. Preeclampsia: pathophysiology, diagnosis and management. Vasc. Health Risk Manag. 2011;7:467-74.

4. Agapov IA, Sadchikov DV, Prigorodov MV. Patogenez gestoza [Gestosis pathogenesis]. Saratovskiy nauchno-meditsinskiy zhurnal. 2011. 7;4:813-6. (In Russian).

5. Duhig KE, Myers J, Seed PT et al. Placental growth factor testing to assess women with suspected pre-eclampsia: a multicentre, pragmatic, stepped-wedge cluster-randomised controlled trial. The Lancet. 2019. 4;393(10183):1807-18. doi: 10.1016/S0140-6736(18)33212-4.

6. Boulanger $H$, Lefevre $G$, Ahriz SS et al. Potential value of placental angiogenic factors as biomarkers in preeclampsia for clinical physicians. Nephrologie \& therapeutique. 2019; 1101:1-18. doi: 10.1016/j. nephro.2018.10.005.

7. Reshetniak 00, Nikitina N0. Khromatohrafichni ta testovi metody analizu: navchalnyi posibnyk: u 2 ch. [Chromatographic and test methods of analysis: textbook: in 2 parts] Testovi metody analizu. Kharkiv: 2012, p. 54-82. (In Ukrainian).

This work is a fragment of the research work of the department of obstetrics and gynecology № 2 of the Vinnitsa National Medical University named after. MI Pirogov "Diagnosis, treatment and prevention of reproductive health disorders of women of different age groups with further prediction of the course of pregnancy, childbirth and the state of newborns" (state registration number 0110U005217).

\section{ORCID and contributionship:}

Pavlo V. Yavorskyi - 0000-0002-5369-9164 A,B,C,D

Vitalii M. Zozulia - 0000-0002-6696-5599 C

Oleh Ya. Vanchuliak - 0000-0003-0243-1894 ${ }^{E}$

Marta S. Garazdiuk - 0000-0003-1536-4440 ${ }^{F}$

\section{Conflict of interest:}

The Authors declare no conflict of interest

\section{CORRESPONDING AUTHOR}

\section{Pavlo V. Yavorskyi}

Nursing Department of Municipal Higher Educational Establishment "Zhytomyr Medical Institute" of Zhytomyr Regional Council, Velyka Berdychivska, str. 46/15. Zhytomyr, 10002, Ukraine tel: +380505040911

e-mail:pavel_va@ukr.net

Received: 17.04 .2019

Accepted: 15.11 .2019

\footnotetext{
A - Work concept and design, B - Data collection and analysis, C - Responsibility for statistical analysis,
} D -Writing the article, $\mathbf{E}$ - Critical review, $\mathbf{F}$ - Final approval of the article 